\title{
House of Marketing Quality Using the House of Quality to Develop Marketing Strategies
}

Bayram Aslan, RWTH Rheinisch Westfälische Technische Hochschule, Aachen, Germany Helmut H. Hergeth, (E-mail: hhh@ncsu.edu), NC State University

\begin{abstract}
The paper presents a Model for Customer Oriented Marketing Strategies, using the House of Quality Approach. The model is presented with an example of Spinning Machinery Marketing.
\end{abstract}

\section{INTRODUCTION}

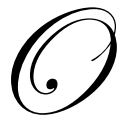

ne of the fundamental problems in marketing is a lack of productivity measures or accountability. Typically productivity, efficiency, and effectiveness measures are applied to manufacturing environments, especially those with high labor content. As cost factors shift in relevance from labor to overhead, productivity of knowledge workers and service workers, and corporate overhead cost becomes increasingly relevant as a growing portion of corporate cost, marketing productivity becomes an increasingly relevant topic. While marketing productivity has been mentioned as a topic already in the 1950s and 1960s, (e.g., Buzzell, 1957, Dean, 1960, Sevin, 1965), marketing departments never underwent the scrutiny that manufacturing and production were exposed to. At the same time, operations management started to emphasize customer focus, and the increased relevance of new product development led to tools that brought customer focus and productivity together for manufacturing, such as Total Quality Management, the House of Quality, Quality Function Deployment matrix, etc.

While marketing provided a lot of input into product development, the customer focus and productivity of marketing was rarely in question. However, the area of industrial marketing already sees a lot of cooperation between marketing and engineering and thus provides an opportunity to use some of the traditional engineering tools and apply them to marketing. The paper applies the House of Quality approach to marketing strategies to create a House of Marketing Quality.

\section{HOUSE OF QUALITY OVERVIEW}

The basic concept of the House of Quality is conceptual framework that links customer requirements to technical engineering parameters and provides the means for inter-functional planning and communication (Hauser and Clausing, 1988; Xie, Tan, and Goh, 2003). The concept is shown in Figure 1, showing the characteristic house shape with the center room focusing on the relationship between the customer requirements and the technical descriptors. This central room houses the quality deployment matrix or the "voice of the customer". Here customer requirements or attributes are translated into technical characteristics (Xie, Tan, and Goh, 2003), engineering characteristics (Hauser and Clausing, 1988), or manufacturing steps (Hergeth, 2002, 2004). The other areas of the house serve to show prioritized customer requirements, prioritized technical descriptors, and interrelationships that will help in the planning process. 
Applied to real life scenarios there may be multiple steps (or houses), where customer characteristics (WHATs) get translated into engineering characteristics (HOWs), then the engineering characteristics become customer requirements (WHATs) for specific parts, and the part characteristics are the HOWs, and so on, through to the final production requirements.

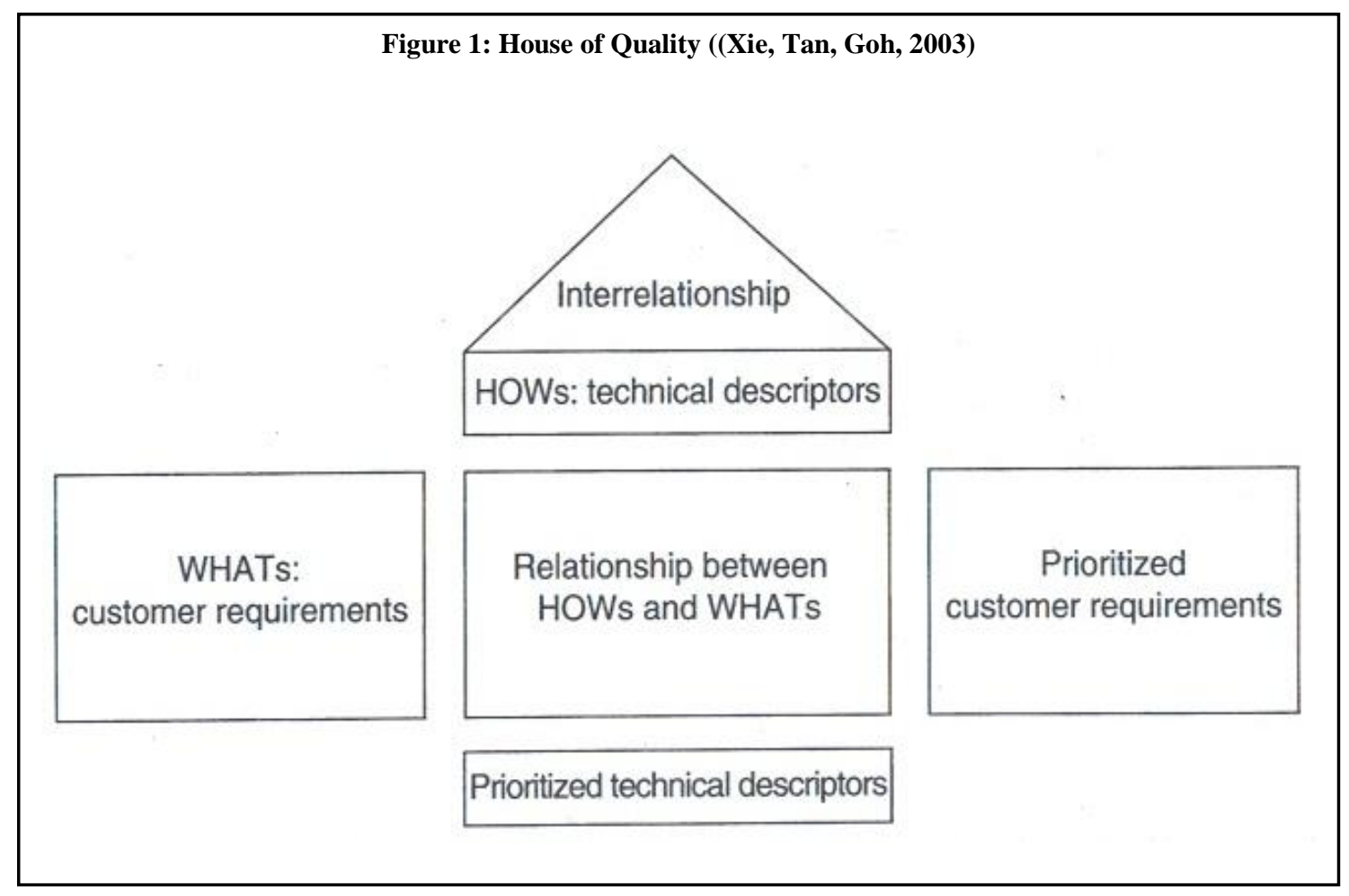

\section{House of Marketing Quality - Customer Requirements}

Using of the House of Quality approach for marketing strategies is an attempt to structure the decision on marketing strategy components around customer requirements. While traditionally marketing implies a customer focus, marketing strategy decisions do not always keep this focus, and a structured approach may be very helpful.

The basic idea of the approach is to keep the WHATs as customer requirements in mind, but link them to marketing objectives and marketing strategy components on the HOWs side of the Quality Deployment Matrix. This process requires in a first step to identify and describe the customer requirements and to rank these requirements. This ranking needs to be weighed by also ranking the customer by relevance to the company. Within the relationship matrix these requirements and then linked to marketing strategies (HOWs) to evaluate how they may address costumer requirements. The goal is not to develop a product that solves customer problems, but rather to develop a marketing strategy that creates a good customer relationship, and at the same time staying within a given budget.

The necessary steps in developing such a House of Marketing Quality are illustrated using the example of a spinning machine manufacturer focusing on the German market for spinning equipment, specifically rotor spinning equipment. The example has been developed with the help of Schlafhorst Saurer GmbH \& Co. KG, but it is for illustration purposes only and neither reflects the actual marketing strategies of the company nor provides a complete list of customer requirements. Preliminary steps involve identifying the target market and identifying competitors within the target market. The first step towards the actual House of Marketing Quality then is surveying the customers to collect data on customer requirements. This step tries to list the WHATs in different layers: 
Primary customer requirements are typically rather vague and general, and they are specified as secondary customer requirements. These secondary customer requirements provide more detail, but are not yet directly actionable. Specific, actionable requirements are tertiary requirements. An example of one of these customer requirements is shown in Figure 2.

\begin{tabular}{|c|c|c|}
\hline \multicolumn{3}{|c|}{ Figure 2: Example of a Customer Requirement } \\
\hline \multicolumn{3}{|r|}{$\mathrm{c}_{\text {req }}$} \\
\hline \multicolumn{3}{|c|}{ Customer Requirements (Needs \& Expectations) } \\
\hline Primary & Secondary & Tertiary \\
\hline \multirow{13}{*}{ 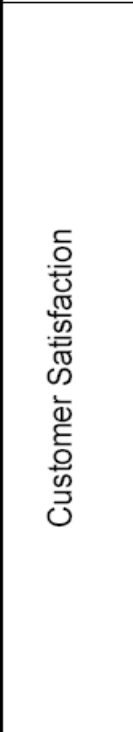 } & \multirow{3}{*}{ Costs } & Acquisition costs \\
\hline & & Maintenance costs/efforts \\
\hline & & Energy consumption \\
\hline & \multirow{3}{*}{ Flexibility } & retooling \\
\hline & & Yarn attributes \\
\hline & & Roving attributes \\
\hline & \multirow{5}{*}{$\begin{array}{l}\text { Production } \\
\text { attributes }\end{array}$} & Piecing Quality \\
\hline & & Yarn quality \\
\hline & & Bobbin quality \\
\hline & & Service \\
\hline & & Operability \\
\hline & \multirow{2}{*}{$\begin{array}{c}\text { Psycological } \\
\text { criteria }\end{array}$} & Brand image \\
\hline & & Design \\
\hline
\end{tabular}

In the example, $\mathrm{c}_{\mathrm{req}}$ describes the cost of finding customer requirements, which typically is part of the marketing budget. The list of customer requirements and their secondary and tertiary levels is typically establishes with the help of customers and the sales department. In the survey customers then rank the importance of the specific (tertiary) attributes on a scale of 1 to 5 or 1 to 10 . Each of the customer requirements is ranked by every customer surveyed. At the same time, the company may value different customers' opinions differently, depending on the importance of a particular customer to the company. Thus the customers are assigned different weights or importance factors. The customer responses are combined into consensus rankings by one of three methods:

1. Consider the maximum importance ranking only. In this case only the highest score of all the customers is considered for each customer requirement.

2. Calculate an average over all surveyed customers for each customer requirement, giving each customer equal weight.

3. Calculate a weighed average over all surveyed customers for each customer requirement, considering the relative importance of each customer to the company. In this method the consensus ranking $R_{i}$ for each requirement $i$ is calculated as follows: 
$R_{i}=\frac{\sum_{i=1}^{m} r_{i j} I_{j}}{\sum_{j=1}^{m} I_{j}}$

$\left(R_{i}=\right.$ consensus ranking for requirement i)

$\left(\mathrm{r}_{\mathrm{ij}}=\right.$ ranking for requirement $\mathrm{i}$ by customer $\left.\mathrm{j}\right)$

( $\mathrm{I}_{\mathrm{j}}=$ relative importance of customer $\mathrm{j}$ for the company)

The resulting table then looks something like Table 1:

Table 1: Consensus Ranking

\begin{tabular}{|c|c|c|c|c|c|c|c|}
\hline \multicolumn{8}{|c|}{$c_{r e q}$} \\
\hline \multicolumn{8}{|c|}{ Importance Rating } \\
\hline \multirow{3}{*}{$\begin{array}{c}I_{1}=9 \\
c u_{1}\end{array}$} & \multicolumn{3}{|c|}{ Customer Importance } & \multirow{3}{*}{$\begin{array}{c}I_{5}=1 \\
c u_{5}\end{array}$} & \multirow{2}{*}{\multicolumn{3}{|c|}{$\begin{array}{c}\text { Consensus } \\
\text { Ranking Methods }\end{array}$}} \\
\hline & \multirow{2}{*}{$\begin{array}{c}I_{2}=1 \\
\mathrm{cu}_{2}\end{array}$} & \multirow{2}{*}{$\begin{array}{c}I_{3}=3 \\
\mathrm{cu}_{3}\end{array}$} & \multirow{2}{*}{$\begin{array}{c}I_{4}=9 \\
c u_{4}\end{array}$} & & & & \\
\hline & & & & & 1 & 2 & 3 \\
\hline 9 & 10 & 10 & 9 & 10 & 10 & 9.6 & 9.2 \\
\hline 8 & 9 & 9 & 9 & 10 & 10 & 9 & 8.7 \\
\hline 10 & 10 & 10 & 10 & 10 & 10 & 10 & 10 \\
\hline 5 & 6 & 7 & 4 & 7 & 7 & 5.8 & 5 \\
\hline 6 & 8 & 8 & 7 & 9 & 9 & 7.6 & 6.9 \\
\hline 9 & 9 & 10 & 9 & 9 & 10 & 9.2 & 9.1 \\
\hline 8 & 8 & 9 & 7 & 9 & 9 & 8.2 & 7.8 \\
\hline 10 & 9 & 9 & 10 & 10 & 10 & 9.6 & 9.8 \\
\hline 7 & 8 & 8 & 6 & 8 & 8 & 7.4 & 6.8 \\
\hline 6 & 7 & 8 & 7 & 8 & 8 & 7.2 & 6.8 \\
\hline 8 & 7 & 8 & 8 & 7 & 8 & 7.6 & 7.9 \\
\hline 4 & 6 & 5 & 3 & 7 & 7 & 5 & 4 \\
\hline 3 & 5 & 5 & 2 & 6 & 6 & 4.2 & 3.1 \\
\hline
\end{tabular}

Now that there is a consensus measure of how relevant each of the customer requirements is, the customer requirements need to be linked to marketing strategy components. 
Figure 3: Example of Marketing Strategy Components

\begin{tabular}{|c|c|c|c|c|c|c|c|c|c|c|c|}
\hline$C_{\text {mast }}$ & $c_{1}^{1}$ & $c_{1}^{2}$ & & $c_{1}^{2}$ & $c_{2}^{2}$ & $c_{1}^{3}$ & $c_{2}^{3}$ & $c_{1}^{4}$ & $c_{2}^{4}$ & $c_{1}^{5}$ & $c_{2}^{5}$ \\
\hline \multicolumn{12}{|c|}{ Business Marketing Strategy Components } \\
\hline & \multicolumn{3}{|c|}{$\begin{array}{l}\text { Product Planning } \\
\text { and Development }\end{array}$} & \multicolumn{2}{|c|}{ Distribution } & \multicolumn{2}{|c|}{ Service/ Sales } & \multicolumn{2}{|c|}{$\begin{array}{l}\text { Advertising/ } \\
\text { Promotion }\end{array}$} & \multicolumn{2}{|c|}{ Pricing } \\
\hline & 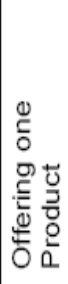 & 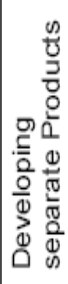 & & 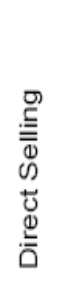 & 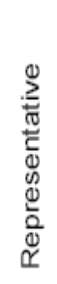 & 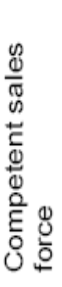 & $\begin{array}{l}0 \\
0 \\
2 \\
0 \\
0 \\
0 \\
\frac{0}{\pi} \\
0 \\
\frac{1}{0} \\
\stackrel{4}{4} \\
\varangle\end{array}$ & $\begin{array}{l}\frac{n}{c} \\
\stackrel{0}{\frac{0}{0}} \\
\frac{0}{\frac{1}{x}} \\
\dot{x}\end{array}$ & 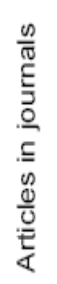 & 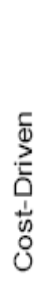 & 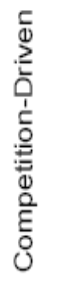 \\
\hline $\begin{array}{l}\text { Acquisition } \\
\text { Costs }\end{array}$ & घ & - & & $\square$ & - & & $\square$ & & & घ & - \\
\hline $\begin{array}{c}\text { Maintenance } \\
\text { Costs }\end{array}$ & - & - & & & & & घ & & & $\boldsymbol{\Delta}$ & घ \\
\hline \begin{tabular}{c|} 
Energy \\
Consumption
\end{tabular} & $\Delta$ & $\Delta$ & & & & & & & & $\Delta$ & \\
\hline Retooling & - & - & & $\square$ & & $\square$ & $\boldsymbol{\Delta}$ & $\square$ & $\Delta$ & $\square$ & 一 \\
\hline $\begin{array}{c}\text { Yarn } \\
\text { Attributes }\end{array}$ & $\boldsymbol{\Delta}$ & $\boldsymbol{\Delta}$ & & & & $\Delta$ & $\square$ & $\Delta$ & - & - & - \\
\hline $\begin{array}{c}\text { Roving } \\
\text { Attributes }\end{array}$ & $\boldsymbol{\Delta}$ & $\boldsymbol{\Delta}$ & & & & $\Delta$ & $\square$ & & - & - & $\square$ \\
\hline $\begin{array}{l}\text { Piecing- } \\
\text { Quality }\end{array}$ & घ & घ & & & & $\Delta$ & $\square$ & & - & $\boldsymbol{\Delta}$ & $\square$ \\
\hline Yarn Quality & $\boldsymbol{\Delta}$ & $\boldsymbol{\Delta}$ & & & & $\Delta$ & $\square$ & $\Delta$ & $\boldsymbol{\Delta}$ & $\boldsymbol{\Delta}$ & $\square$ \\
\hline $\begin{array}{l}\text { Bobbin } \\
\text { Quality }\end{array}$ & घ & घ & & & & $\Delta$ & $\square$ & $\Delta$ & - & $\boldsymbol{\Delta}$ & $\square$ \\
\hline Service & $\square$ & - & & 一 & $\square$ & $\boldsymbol{\Delta}$ & - & $\Delta$ & $\Delta$ & $\Delta$ & $\Delta$ \\
\hline Operability & घ & 口 & & & & & $\square$ & $\Delta$ & & $\Delta$ & $\Delta$ \\
\hline Brand Image & $\square$ & - & & $\boldsymbol{\Delta}$ & - & 口 & $\boldsymbol{\Delta}$ & $\boldsymbol{\Delta}$ & - & $\square$ & - \\
\hline Design & घ & घ & & & & & & & & & \\
\hline
\end{tabular}




\section{HOUSE OF MARKETING QUALITY - MARKETING STRATEGY COMPONENTS}

While Table 1 shows the consensus rankings for the WHATs, the central room in the House of Marketing Quality links these WHATs with the HOWs, in this case with the marketing strategy components. The marketing strategy components considered in this example are Product Planning and Development, Distribution, Service, Promotion, and Pricing. Each of these components has several marketing management component alternatives. An example of these strategy components and the component alternatives is shown in Figure 3.

In this matrix customer requirements are linked to marketing strategy components. This is where the House of Marketing Quality departs from the traditional QFD matrix. With the help of team members from marketing, sales, and customer service as well as other functional areas of the company each marketing strategy components is linked to each customer requirement and their relationship is ranked. Typically the degree of relationship is represented by a symbol (see Figure 3 for an example), ranking from "no relationship" to "very strong relationship". If there is no relationship, the cell remains empty. It may be useful to include customer representatives or intermediaries in the team that constructs this relationship analysis.

Completing this relationship matrix can take a very long time as each individual potential relationship is addressed separately by the team. An empty row would indicate that the customer requirement is not being addressed by any of the marketing strategy components and an empty column would indicate that this marketing strategy component is not relevant to any of the customer requirements. In a sense, the QFD matrix provides a playbook as to which marketing strategy components can be used to address specific customer requirements. This is important since different customers put different weights on the requirements, and this way customer specific marketing strategies can be applied.

For the overall marketing strategy the different strategy components and alternatives are weighted to obtain prioritized marketing strategy components. This happens in a matrix below the QFD matrix, in the basement of the House of Marketing Quality. There are four rows in this basement, first the absolute weight of each component that is based on assigning numerical values to the relationship symbols, and than adding these values up for each marketing component alternative. At the same time we know that not all alternatives are equally easy to implement, and we also know that some strategies are more expensive than others. Adjusting the weight of each alternative with a degree of difficulty of implementation (the second row of the basement) leads to adjusted weights in the third row that can then be translated into percentage weights in the fourth row. The symbols for Figure 4 are as follows:

\footnotetext{
$w_{g}^{k} \quad:$ weight with which alt $_{g}^{k}$ affects customer requirements

$d_{g}^{k} \quad$ : degree of difficulty for implementing $a l t_{g}^{k}$

$w a_{g}^{k} \quad$ : weight with which $a l t_{g}^{k}$ affects customer requirements adjusted

$w p_{g}^{k} \quad$ : percentage adjusted weight of $a l t_{g}^{k}$
} 
Figure 4: Prioritized Marketing Strategy Components

\begin{tabular}{|c|c|c|c|c|c|c|c|c|c|c|c|c|c|c|c|c|c|}
\hline \multicolumn{18}{|c|}{ Business Marketing Strategy Components } \\
\hline & \multicolumn{5}{|c|}{ mast $_{1}$} & \multirow{2}{*}{$\begin{array}{l}\cdots \\
\cdots \\
\cdots\end{array}$} & \multicolumn{5}{|c|}{ mast $_{k}$} & \multirow{2}{*}{$\begin{array}{l}\cdots \\
\ldots \\
\cdots\end{array}$} & \multicolumn{5}{|c|}{ mast $_{q}$} \\
\hline & $a l t_{1}^{1}$ & $\cdots$ & alt $_{g}^{1}$ & .. & $a_{1 h}^{1}$ & & alt ${ }_{1}^{\prime}$ & ... & alt $t_{g}^{k}$ & $\cdots$ & alt $_{h}^{k}$ & & alt $t_{1}^{q}$ & $\cdots$ & $a l t_{g}^{q}$ & $\ldots$ & alt $t_{h}^{q}$ \\
\hline absolute weight & $w_{1}^{1}$ & $\cdots$ & $w_{g}^{1}$ & $\cdots$ & $w_{h}^{1}$ & $\cdots$ & $w_{1}^{k}$ & $\cdots$ & $w_{g}^{k}$ & $\cdots$ & $w_{h}^{k}$ & $\cdots$ & $w_{1}^{q}$ & $\cdots$ & $w_{g}^{q}$ & $\ldots$ & $w_{h}^{q}$ \\
\hline $\begin{array}{l}\text { difficulty of } \\
\text { Implementation }\end{array}$ & $d_{1}^{1}$ & $\cdots$ & $d_{g}^{1}$ & $\cdots$ & $d_{h}^{1}$ & $\cdots$ & $d_{1}^{k}$ & $\cdots$ & $d_{g}^{k}$ & $\cdots$ & $d_{h}^{k}$ & $\cdots$ & $d_{1}^{q}$ & $\cdots$ & $d_{g}^{q}$ & $\cdots$ & $d_{h}^{q}$ \\
\hline adjusted weight & $w a_{1}^{1}$ & $\cdots$ & $w a_{g}^{1}$ & $\cdots$ & $w a_{h}^{1}$ & $\cdots$ & $w a_{1}^{\prime}$ & $\cdots$ & $w a_{g}^{k}$ & $\cdots$ & $w a_{h}^{k}$ & $\cdots$ & $w a_{1}^{q}$ & $\ldots$ & $w a_{g}^{q}$ & $\ldots$ & $w a_{h}^{q}$ \\
\hline $\begin{array}{l}\text { percentage } \\
\text { weight }\end{array}$ & $p w_{1}^{1}$ & $\ldots$ & $p w_{g}^{1}$ & $\cdots$ & $p w_{h}^{1}$ & $\cdots$ & $p w_{1}$ & ... & $p w_{g}^{k}$ & $\ldots$ & $p w_{h}^{k}$ & $\cdots$ & $p w_{1}^{q}$ & $\ldots$ & $p w_{g}^{q}$ & $\ldots$ & $p w_{h}^{q}$ \\
\hline
\end{tabular}

The basement provides a summary of the relative importance of different marketing strategy components in addressing weighted customer requirements. This is an important tool when it comes to deciding on alternative strategy components under budget restraints.

\section{Interrelationships between Marketing Strategy Components}

Different marketing strategy components may influence each other, either positively in the sense that they support each other, or negatively in the sense that they are competing with each other. Of course it is also possible that they do not have any influence on each other at all. The interrelationship matrix takes the shape of a triangle or the pitched roof of the House of Marketing Quality, and it summarizes all positive and negative relationships between the strategy component alternatives, based on the judgment of the team. An example is shown in Figure 5. 


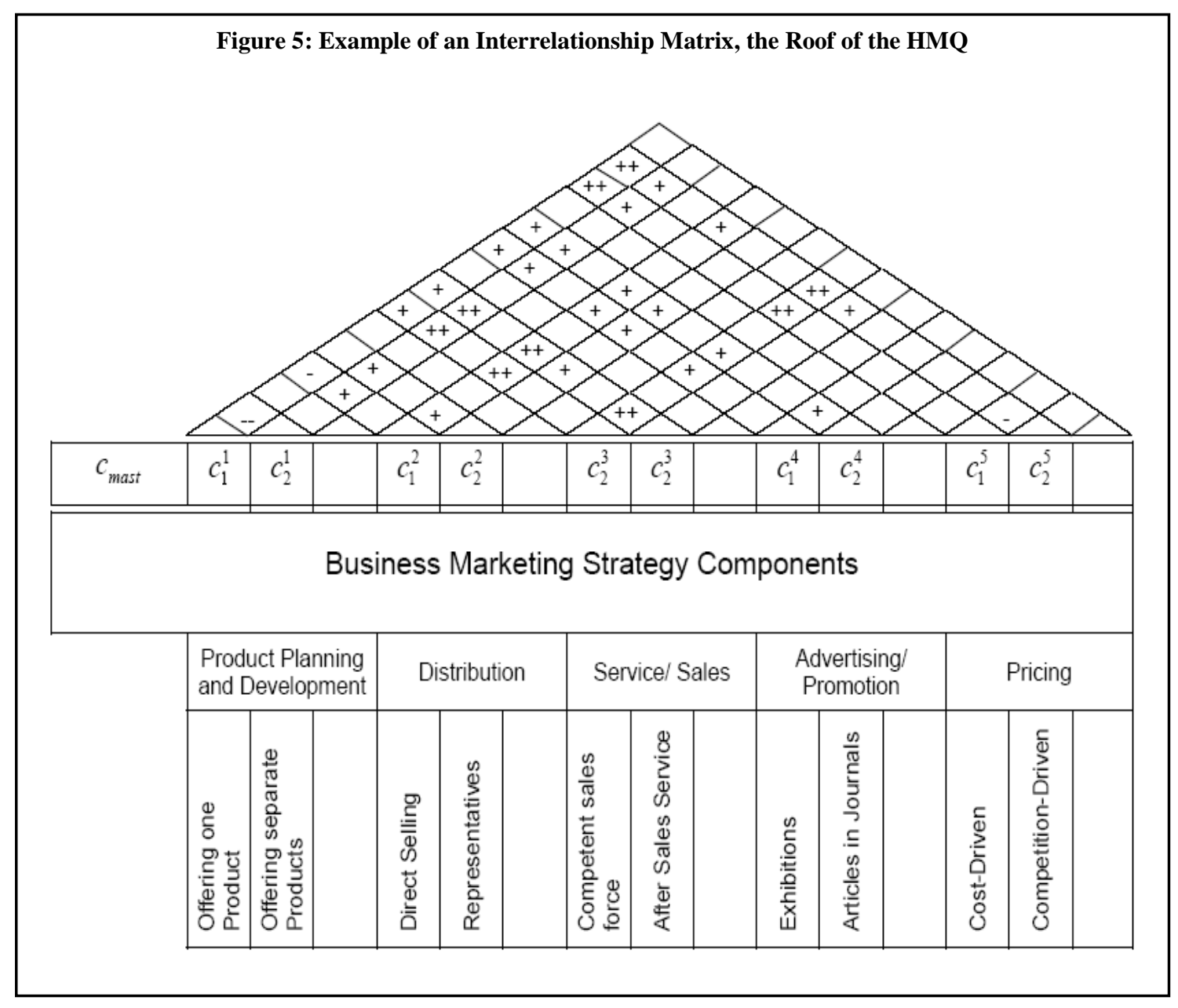

While the interrelationship matrix is not directly linked to customer requirements, it does show which components or alternatives have to be coordinated in order to achieve an effective marketing mix. The example shows things like a strong positive relationship between a competent sales force and strong after-sales service or a limited compatibility between direct selling and offering only one product. Areas that are not interrelated have less of a need for coordination.

\section{COMPETITIVE ASSESSMENT}

To the right side of the center room we can create some competitive assessments, charting the perceptions customers have about the company relative to competitors for each of the customer requirements. This is the garage within the House of Marketing Quality. This assessment is done for each customer requirement by the customers as well as by the company (self assessment), resulting in a consensus ranking. At the same time the customers can share their perceptions of how specific competitors rank for the requirements. This will lead to a profile showing the company relative to the competition, showing in what aspects the company is considered better or worse and thus showing areas with improvement opportunities, i.e., it provides some competitive benchmarking. Figure 6 shows the competitive assessment and the competitive ranking for the example. 


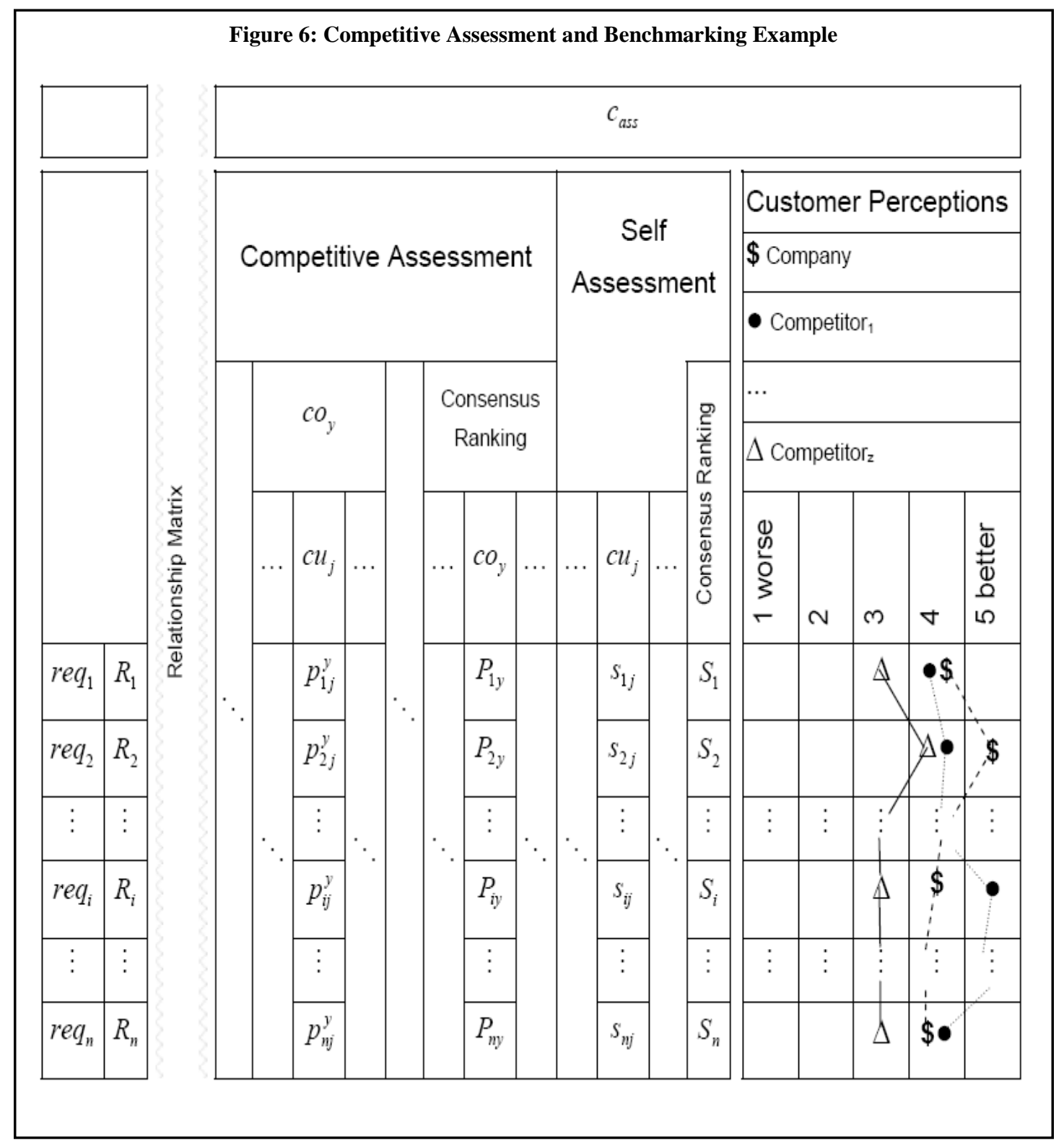

In Figure 6 the following symbols are used:

$c_{\text {ass }} \quad$ : the costs for assessing marketing activities

$z \quad:$ the number of the considered competitors

co $o_{y}:$ the $y$ th competitor, $y=1, \ldots, z$

$p_{i j}^{y} \quad:$ the $j$ th customers perceived quality of $r e q_{i}$ from $c o_{y}$

$P_{i y} \quad:$ the calculated consensus rank of $\mathrm{req}_{i}$ of $\mathrm{co}_{y}$

$S_{i j} \quad:$ the $j$ th customers perceived quality of the company

$S_{i} \quad$ : the calculated consensus rank of $r e q_{i}$ of the company 
A similar competitive assessment can be performed for the marketing strategy components, ranking the company and the competitors for each of the components. The rankings are plotted below the relationship matrix, considering the perceived quality of each requirement and the respective weight the strategy component has for the requirement. This provides a benchmark analysis of the company based not on customer requirements but on the use of marketing strategy components. Just like the requirement benchmarking it shows opportunity for improvements. Figure 7 shows this sub-basement.

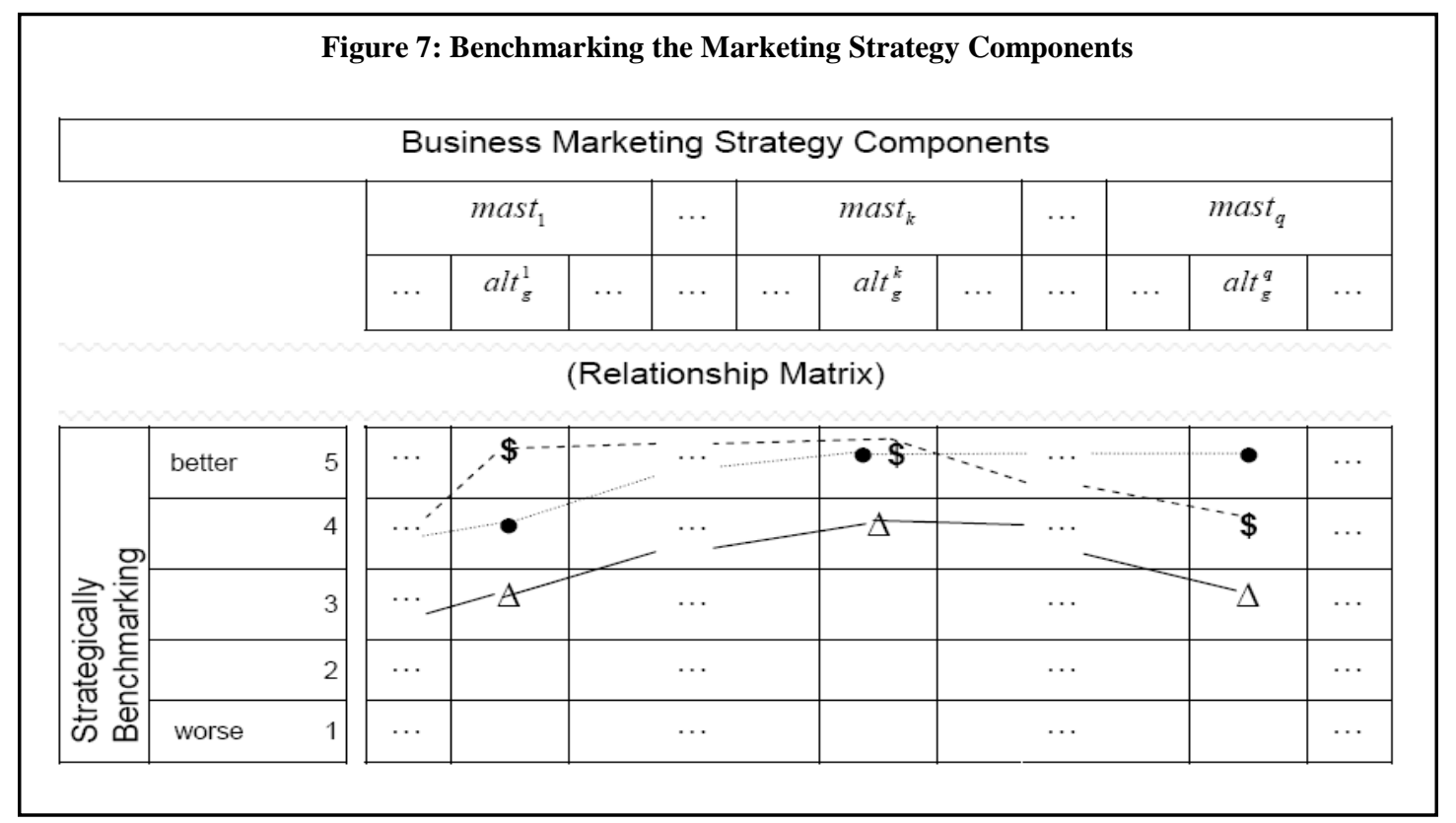

\section{SUMMARY AND CONCLUSIONS}

Figure 8 shows the complete House of Marketing Quality with the customer requirements on the left, the marketing strategies and alternatives in the ceiling, and their relationship in the center. The basement evaluates and compares the marketing tools available to the company and how it benchmarks against the competition, on the right it shows how the company benchmarks against the competition based on customer requirements, and in the roof it shows how different marketing strategy components are interrelated.

The House of Marketing Quality and within it the Quality Function Deployment Matrix provide a systematic approach for developing and evaluating a customer oriented marketing strategy. Used in a company this tool ensures that marketing strategy components are focusing on customers and address customer requirements. While this is often assumed to be the case with marketing efforts, the structured approach greatly reduces chances for "hobby marketing efforts" that fail to keep the customer in focus.

Additionally, the House of Marketing Quality provides communication tool within company to focus strengths and resources. This is a very similar result as originally intended for the House of Quality, however now with a focus on marketing strategy components rather than product features. 


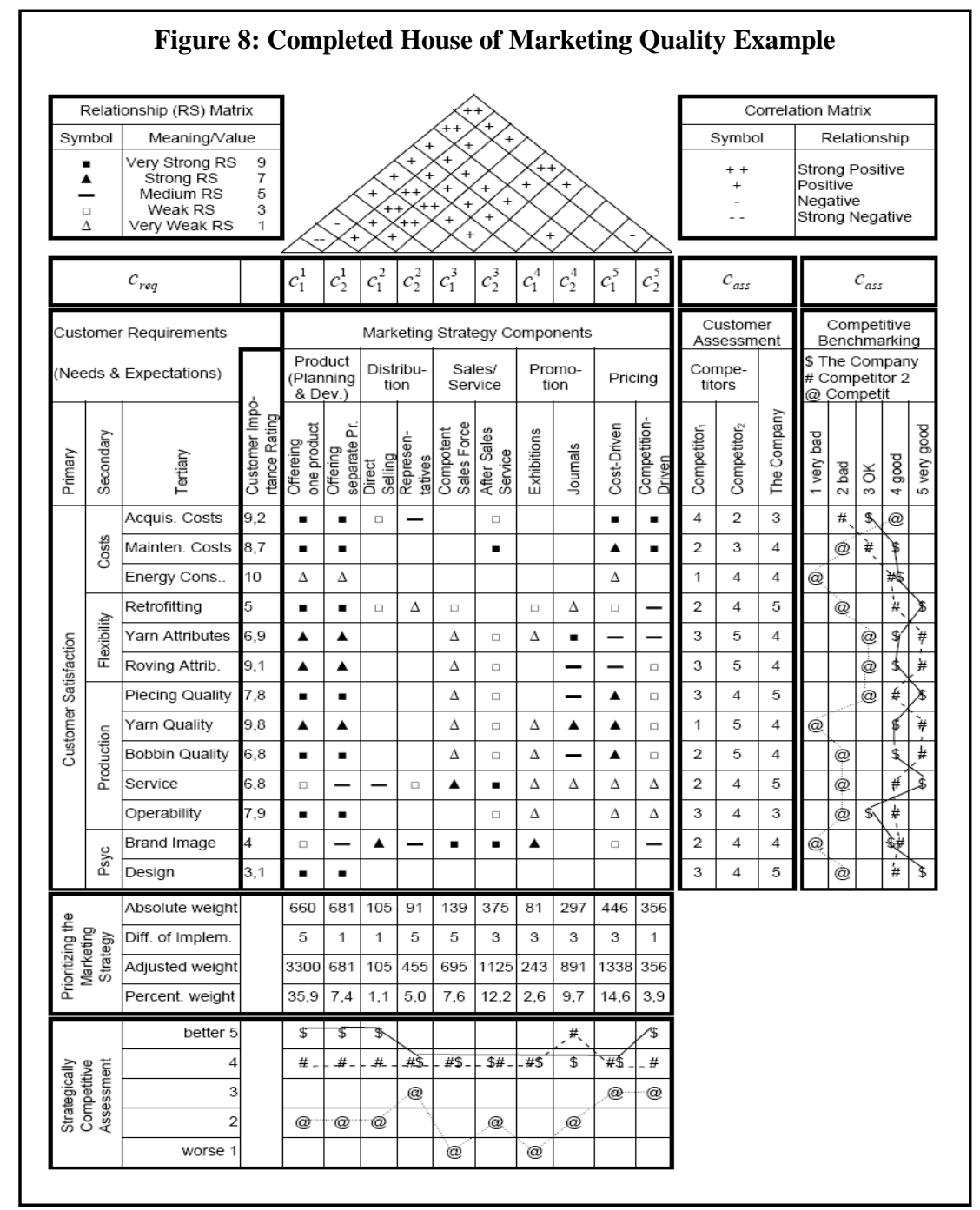

\section{BIBLIOGRAPHY}

1. $\quad$ R. D. Buzzell, Marketing Productivity, PhD Dissertation Ohio State, 1957.

2. J. Dean, Marketing Productivity and Profitability, Productivity Measurement Review, Number 20, February 1960, pp. $47 \mathrm{ff}$.

3. J. R. Hauser and D. Clausing, The House of Quality, Harvard Business Review, May-June 1988, pp. 63 ff.

4. H. Hergeth, Target Costing in the Textile Complex, Journal of Textile and Apparel, Technology and Management, Volume 2, Issue 4, Fall 2002.

5. H. Hergeth, Launching Products towards the Right Target, Journal of the Textile Institute, Vol. 95, Numbers 1-6, 2004, pp. $251-259$.

6. $\quad$ C. H. Sevin, Marketing Productivity Analysis, McGraw Hill, 1965.

7. Min Xie, Kay-Chuan Tan, Thong Ngee Goh, Advanced QFD Applications, Milwaukee, Wis.: American Society for Quality, Quality Press, 2003. 
Journal of Business \& Economics Research - November 2007

Volume 5, Number 11

NOTES 